\title{
The Life Times of Polymer Composites in Construction
}

\author{
Urs Meier $^{\mathrm{a}}$ \\ ${ }^{a}$ Empa, Swiss Federal Laboratories for Materials Science and Technology \\ Ueberlandstrasse 126, CH 8600 Dubendorf, Switzerland
}

\begin{abstract}
This paper discusses examples that prove the long-term reliability of Fiber Reinforced Polymers (FRP) under extreme loading conditions and outdoor weathering. Results of polymer/steel-composite anchorage systems, Glass Fiber Reinforced Polymer (GFRP) plates and shells, GFRP box girders, Carbon Fiber Reinforced Polymer (CFRP) posttensioning tendons and CFRP stays are going to be presented.
\end{abstract}

Keywords: CFRP; box-girder; GFRP; shell; tendon; creep; stress-relaxation.

PACS: 07.10.Lw, 42.81.Qb, 62.20.Hg, 62.20.mt, 62.40.+I, 81.05.U-, 82.20.Rp.

\section{INTRODUCTION}

The spirit of the 1960's and 1970's was in Europe bad for technically demanding applications of polymers and FRP. This was in remembrance of World War II. "Plastics" and FRPs were in the mind of most people poor performing replacement materials, and there was no trust in this kind of materials, especially not as structural components for reliable long-term applications. Therefore, in 1972 Empa, initiated a R\&D program for structural components made of fiber composites. The goal of this program was to build up confidence in the civil engineering community for these modern materials.

\section{POLYMER/STEEL-COMPOSITE ANCHORAGE SYSTEMS}

For advanced suspended structures classical metal based cable anchorage systems had to be replaced by polymer based systems to improve the fatigue performance $[1,2]$. The steel wires are anchored in a steel cylinder with a conical inner surface, in which the cavities are filled under vibration with epoxy resin, small steel balls and zinc dust (Figure 1), whereupon this filler material is cured by heating.

Series of epoxy bonded parallel wire steel cables had been tested for the project of the Kurt Schumacher cable stayed bridge in Mannheim-Ludwigshafen crossing the river Rhine and for the suspended roof of the main stadium and indoor arenas for the 1972 Summer Olympic Games in Munich [1,2]. These epoxy/bond type anchorages reached in the fatigue experiments a fatigue stress range (double amplitude) greater than $300 \mathrm{MPa}$ and were able to withstand the ultimate breaking load of the steel wire bundles with adequate safety. Fatigue failures of wires due to very high amplitudes were statistically well distributed over the whole free length of the steel cables and not concentrated near the epoxy/bond anchorage heads.

Polymer/steel-composite anchorage systems are now since more than forty-five years without any problems under high sustained and fatigue loads in operation in practice. They especially proof the long-term reliability of epoxy systems in structural applications.

\section{GFRP SHELLS AND PLATES EXPOSED TO OUTDOOR WEATHERING}

Heinz Isler [3] started 1955 with the construction of GFRP domes. All of them showed a high degree of translucency. In 1967 Isler designed and built out of "flat GPRP honeycomb plates" a fold structure with spans of about $20 \mathrm{~m}$ based on triangles covering the yard of the Middle School in Geisslingen, Germany (Figure 2a). A great 
advantage of this kind of construction is beside light weight and a high degree of translucency the pre-fabrication and therefore a fast installation.

This pioneering GFRP shells and plates are - except for the example in Figure $2 \mathrm{a}$ - still in use. They survived high wind loads, UV-radiation and small amplitude fatigue cycling like in the case of a hydraulic power plant. Due to UV attack there is after more than forty years some degradation of the gelcoat surface, however not of the structural reliability. After such a long time the surface should be repainted with a UV resistant translucent paint. In some cases this has already been done with relative little effort. For the roof of the Middle School in Geisslingen (Figure 2a) it was too late. It had to be replaced in 2014 due to loss of translucence (Figure 2b). From a structural, water- and windproof point of view it was still fully satisfactory. The replacement is a one-to-one copy of the original roof.

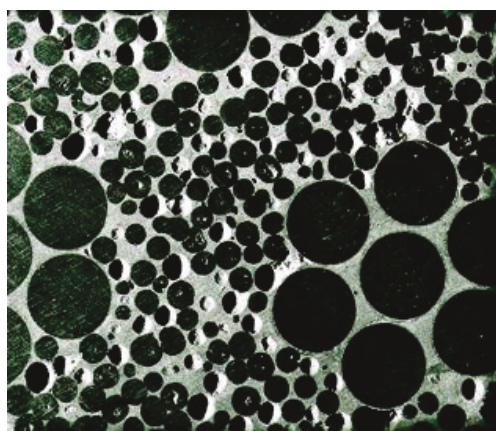

FIGURE 1. Cross section of an polymer anchorage system. Large circles are steel wires of $6 \mathrm{~mm}$ diameter, the small circles steel balls of about $2 \mathrm{~mm}$ diameter. The space in between is cured epoxy resin.

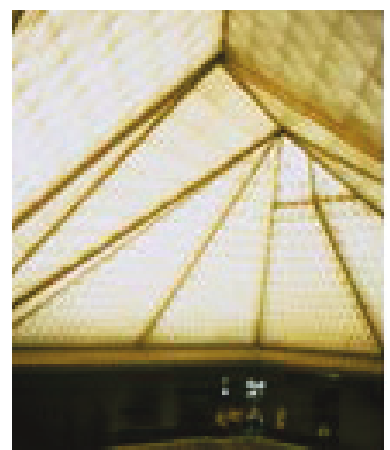

FIGURE 2a. Section of the GFRP fold structure roof of the Middle School in Geisslingen in 1967.

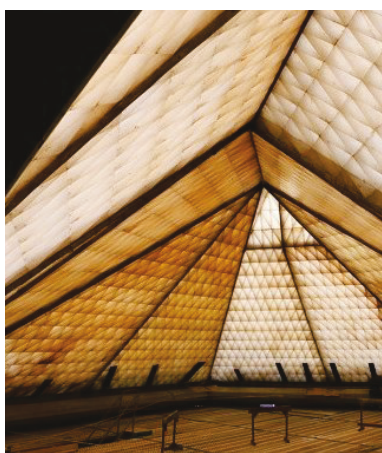

FIGURE 2b. Section of the same roof as in Figure 2a in 2014 Replacement due to loss of translucence with a one-to-one copy of the original roof.

\section{GFRP BOX GIRDERS UNDER EXTREME LONG TERM LOADING}

The construction of the box girders with a length of 3.00 meters is shown in Figures 3 and 4 . The flanges are fabricated of unidirectional profiles, and the webs of filament-wound laminates. E-glass rovings were employed as reinforcement fibers and epoxy resin as matrix [4]. The span of all girders was $2.80 \mathrm{~m}$ in loading experiments.

Girder No. 5 was tested in fatigue for 100 million cycles with a frequency of $2.0 \mathrm{~Hz}$ (1.6 years), with a lower load limit of $\mathrm{F}_{\min }=10 \mathrm{kN}$ ( $5 \%$ of ultimate load) and an upper load limit of $\mathrm{F}_{\max }=40 \mathrm{kN}$ (20\% of ultimate load) per loading point in a four-point bending experiment. Each loading point is $0.70 \mathrm{~m}$ apart from the next support. Under the given conditions, no damage or change in the bending stiffness could be observed over the entire course of the test. This is not too surprising, since the calculated load for first ply failure was $60 \mathrm{kN}$ (30\% of ultimate load) per loading point.

For the girder No. $6 \mathrm{~F}_{\min }=10 \mathrm{kN}$ remained unchanged but $\mathrm{F}_{\max }$ was raised to $60 \mathrm{kN}$ corresponding to the first ply failure load. After four million cycles, cracks appeared on the matrix-rich surface of the tensile flange perpendicular to the $\mathrm{x}$-axis. These cracks were studied with a stereo microscope while under upper load $\mathrm{F}_{\max }=60 \mathrm{kN}$. It was found that the cracks were confined to the matrix surface and did not involve the fibers. The outside $\pm 45^{\circ}$ filaments bridged the cracks. After 38 million cycles, the first delamination zones, approximately finger-nail size appeared. These zones were located in the region of the load points between the unidirectional compression-flange and the outside $\pm 45^{\circ}$ plies. They enlarged further by approximately $70 \%$ up to 100 million cycles. At this stage a decrease of bending stiffness of about $2 \%$ was observed.

After completion of 100 million fatigue cycles with $F_{\max }=60 \mathrm{kN}$ the girder No. 6 was subjected to an extreme long-term creep test. The loading arrangement was (and is even now, since the experiment is still going on) also four-point bending, similar to the monotonous static and the fatigue loading. The load $\mathrm{F}=60 \mathrm{kN}=$ constant was accomplished ( $30 \%$ of ultimate load) with a dead load (lead ingot) arrangement. During the first 20,000 hours there were relative high creep rates, as shown in Figure 5.

Now after more than 25 years of constant loading these creep rates are diminishing to zero (Figure 5). The deflections given in Figure 5 have been measured in the center of the girder in the region of the constant bending 
moment over a gauge length of $1000 \mathrm{~mm}$. These deflections can be correlated with the curvature of the girder. The first $11.4 \mathrm{~mm}$ of deflections at "zero time" have been contributed by the elastic deformation during loading.

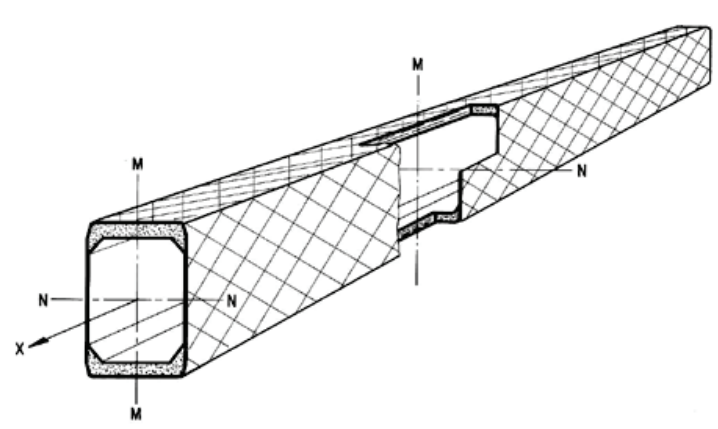

FIGURE 3. Perspective view of GFRP box girder.

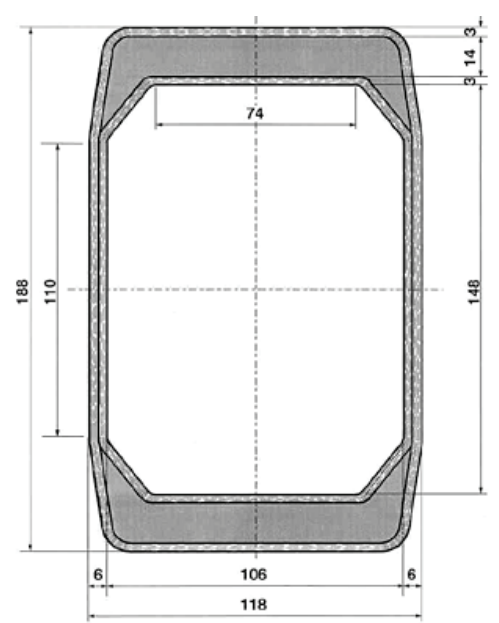

FIGURE 4. Typical cross section of the GFRP box girder.

The excellent long-term static and fatigue behavior is due to the fiber-dominated design of the described box girder system. In no situation does the matrix have a primary load carrying function.

\section{CFRP POST-TENSIONING TENDONS UNDER VERY HIGH SUSTAINED STRESS}

The Verdasio Bridge in the south of Switzerland is a two-lane highway bridge and was built in the seventies. The length of the continuous two-span box girder is $69 \mathrm{~m}$. A large internal post-tensioning steel cable positioned in a concrete web was fully corroded as a result of the use of salt for deicing. It had to be replaced in December 1998 by external CFRP tendons.

The cable load (Figure 6) in function of the time has been measured. This project was as far most interesting as in this case the nominal post-tensioning stress in the cable cross sections is as high as $1610 \mathrm{MPa}$. More similar pilot projects have been presented in $[5,6]$.

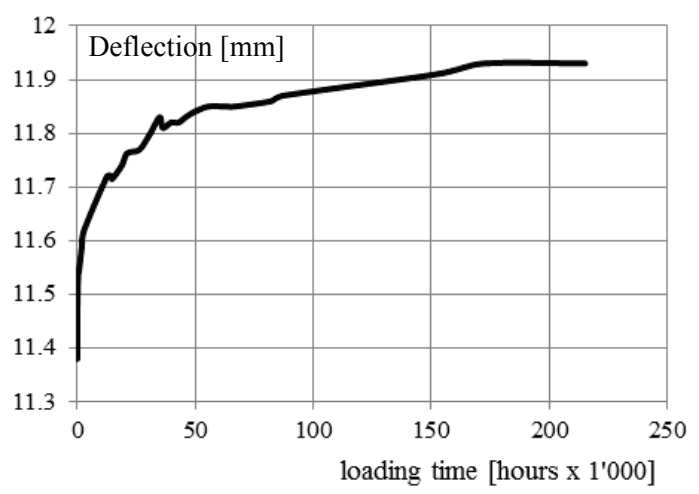

FIGURE 5. Creep behavior of girder No. 6 for a constant loading of $\mathrm{F}=60 \mathrm{kN}$ in each loading point during 25 years.

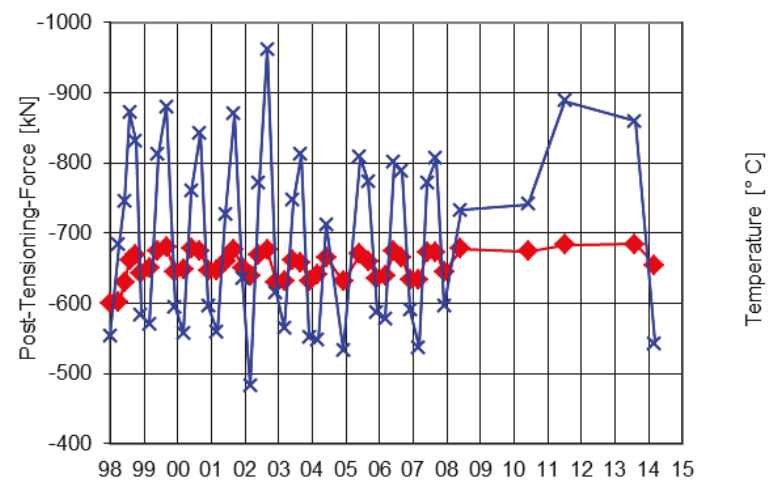

FIGURE 6. Post-tensioning-cable-force (red diamond) and temperature (blue $\mathrm{x}$ ) versus time (17 years) for anchorage \#6. There is no stress relaxation with CFRP cables. Since 2008 the intervals of measurements have been reduced.

Parallel with the seasonal temperature fluctuation there is a fluctuation of the cable force (Figure 6). The coefficient of thermal expansion for the CFRP tendons is about zero. In summertime, when the temperature is high, the concrete of the bridge girder expands. Due to that the CFRP cable force is increasing. In winter it is opposite. 
Most remarkable is that the average of the cable force is a "horizontal straight line". That means there is no stress relaxation. This is surprising and unexpected from a "steel cable point of view", but "no stress relaxation" is a typical property of the carbon fibers. The Verdasio Bridge is one of the best proofs for the outstanding long term performance of highly loaded CFRP tendons.

\section{CFRP STAYS UNDER HIGH FATIGUE LOADING}

Most bridge engineers agree that the corrosion and fatigue resistance of cables for suspended structures have to be enhanced. CFRP could be an excellent solution.

The Stork Bridge, erected in 1996, is situated over the 18 tracks of the railroad station in Winterthur. The CFRP cable type used for the Stork Bridge consists of 241 wires each with a diameter of $5 \mathrm{~mm}$. This cable type was subjected to a load three times greater than the permissible load of the bridge for more than 10 million load cycles. Not any damage was detected. The CFRP cables with their anchorage heads have been equipped by the Empa with conventional sensors and also with state-of-the-art glass fiber optical sensors which provide permanent monitoring to detect any stress and deformation. Since 1996 the CFRP cables of the stork bridge are fully matching all the high expectations [6].

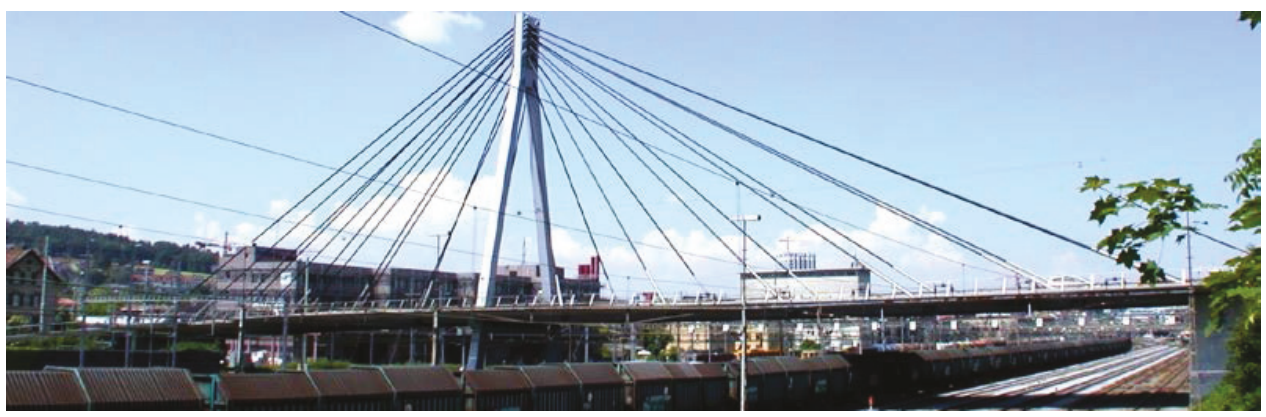

FIGURE 7. Stork Bridge in Winterthur, Switzerland with CFRP stay cables.

\section{CONCLUSIONS}

Empa, the Swiss Federal Laboratories for Materials Science and Technology conducted since 1975 large scale experiments with the goal to build up confidence in the civil engineering community for the long-term reliability of polymers and FRP in structural applications. The examples described in this paper prove that FRPs and polymers are very reliable construction materials, if correctly applied. There is great hope that these modern materials will contribute in future more for a enhanced sustainability in construction. In a further future CFRPs might also contribute to the construction of very long span bridges $[5,7]$.

\section{REFERENCES}

1. U. Meier, A. Rösli, „Versuchseinrichtung für Zugschwellbeanspruchungen an grossen Spannkabeln“, Schweizerische Bauzeitung, Vol. 89, No. 4, Januar 1971, pp. 81-86.

2. U. Meier, „Das Olympiadach in München und die dafür durchgeführten Grossversuche“, Schweizerische Bauzeitung, Vol. 89, No. 16, April 1971, pp. 375-380.

3. U. Meier, "History of FRP in Construction; Heinz Isler: world famous for his concrete shells - however little-known for his pioneering work in FRP“, FRP INTERNATIONAL, Vol. 8, No. 2, April 2011, pp. 6-8.

4. U. Meier, R. Müller, M. Barbezat, G. P. Terrasi, „Box Girders under Extreme Long-Time Static and Fatigue Loading“, Advances in FRP Composites in Civil Engineering, 2011, pp. 348-351.

5. U. Meier, Carbon Fiber Reinforced Polymer Cables: Why? Why Not? What If?, Arabian Journal for Science and Engineering, Vol. 37, 2012, No. 2, pp. 399-411.

6. U. Meier, R. Brönnimann, P. Anderegg, G. P. Terrasi, „20 Years of Experience with Structural Health Monitoring of Objects with CFRP Components“, Nondestructive Testing of Materials and Structures, RILEM Bookseries, 2013, Volume 6, Part 9, pp. 959-976.

7. U. Meier, "Proposal for a carbon fibre reinforced composite bridge across the Strait of Gibraltar at its narrowest site", Proc Instn Mech Engrs B2 IMechE 201, 1987, pp. 73-78. 